\title{
Eco-efficiency as an evaluation method of disproportionate costs within the Water Framework Directive
}

\author{
S. Geyler ${ }^{1}$, L. Laforet ${ }^{1}$, A. Quadflieg ${ }^{2}$ \& R. Holländer ${ }^{1}$ \\ ${ }^{1}$ Institute for Infrastructure and Resources Management, \\ Universität Leipzig, Germany \\ ${ }^{2}$ Hessian Ministry of the Environment, Climate Protection, \\ Agriculture and Consumer Protection, Germany
}

\begin{abstract}
The European Water Framework Directive (WFD) has set the objective of good ecological and chemical status for all European waters by 2027 at the latest. However, exemptions from good status are allowed in cases where economic/social costs outweigh the benefits of water improvement (disproportionality). Eco-efficiency analysis (EEA) is usually applied to evaluate products and processes. The paper argues that EEA can also be used as a methodical approach to evaluate disproportionality of WFD measures. The approach is applied to a potash and magnesium mine discharging effluents into a German river basin (Werra/Weser). Here, the EEA relates water quality improvement to the economic costs of the measures ranking them according to their eco-efficiency. In doing so, EEA structures information on effectiveness and cost-effectiveness of WFD measures, and provides inputs to evaluate affordability and disproportionality of them.
\end{abstract}

Keywords: European Water Framework Directive, disproportionality, affordability, eco-efficiency analysis.

\section{Introduction}

Though the European Water Framework Directive (WFD) has set the objective of good ecological status for all European water bodies by 2015, exemptions in the implementation of the supplementary measures can be allowed for reasons of technical feasibility, natural conditions or cost disproportionality. Derogations can 
be permitted to either extent the deadline of achievement of the objective until latest 2027 or to set less stringent environmental objectives (European Commission [1]).

According to the Common Implementation Strategy of the WFD, even costeffective measures may be disproportionate when they outweigh the benefits of the measure. Additionally, the ability to pay should be considered. However, guidance documents have refrained from giving clear assistance on affordability (e.g. European Commission [2,3]), or have been more concerned with social effects towards households than with ability to pay by sectors (European Commission [4]).

One of the major interest conflicts in the river basin of Werra/Weser in Germany is induced by a salt mining site in Hesse and Thuringia. There, a large producer of potassium- and magnesium-based fertilizers discharges chloride, potassium and magnesium effluents in the Werra affecting the Werra/Weser river system downstream over a length of $500 \mathrm{~km}$. At the same time, the mining company is an important employer in a structurally lagging region. The considered technical measures are cost-intensive and, not surprisingly their effectiveness, affordability and proportionality are subject to discussion (Runder Tisch [5], FGG Weser [6]).

For assessing disproportionality of the measures, CBA may be regarded as a good choice for defining and monetising costs and benefits at societal level, but the instrument has severe drawbacks. Benefits of measures often cannot be monetised, especially benefits of good water status, either due to a lack of data or because elicitation of value statements of stakeholders is a demanding task, e.g. $[3,4,7]$. Furthermore, CBA results are difficult to interpret because of the aggregation of multiple dimensions into a single indicator.

Thus, there is still the need for tools that are easier to implement and are better descriptive and illustrative. Such instruments, however, should be compatible with the welfare economic theory behind CBA and robust when available information is sparse.

The purpose of this paper is (i) to introduce eco-efficiency analysis (EEA) as a possible approach to assess disproportionate costs regarding WFD measures in a comprehensive and comprehendible way and (ii) to present first insights to a case of potash mining effluents in Germany where EEA has been applied to.

The paper is organized as follows: in section 2, general characteristics of the case study are presented. In section three, the application of eco-efficiency to the case study is described using fictive results since the political decision process is still under way. In the final remarks, the lessons learnt are summarised regarding EEA as an evaluation tool. Additionally, although being case specific, two aspects of the assessment are stressed that call for advancement of WFD disproportionality assessment.

\section{WFD and German potash mining}

The Werra Potash mining site in Hesse and Thuringia is a large producer of potassium- and magnesium-based fertilizers, which discharge chloride, potassium 
and magnesium effluents in the Werra affecting the course of Werra/Weser river system over a length of $500 \mathrm{~km}$. With the introduction of dry production technologies in the 80 s, significant volume of effluents has been replaced by solid residuals, which have accumulated in gigantic waste dumps and become a long-term source of emissions due to rainwater run-offs (Runder Tisch [5], FGG Weser [6]).

To decrease salt concentrations in the river system, run-offs from salt-waste dumps must be minimized, on-site production effluents reduced and production even restricted when necessary. However, the management of salt discharge is complicated because of fluctuating river flows and precipitation patterns.

Combinations of those measures are to be evaluated regarding the following aspects: Are they effective in achieving WFD targets regarding water bodies? Which of the measures are cost-effective? Are the costs of the measures affordable for the mining company according to the polluter-pays-principle and proportional for the society?

The following aspects complicate the economic analysis of disproportionality:

- $\quad$ Regional economic importance: The mining company is the only major source of economic activity in an otherwise not very vibrant region.

- $\quad$ Potash mining is a worldwide market: though there is only one potash producer in Germany, it competes with a number of foreign companies from Russia, Canada, Spain and other countries that, for a variety of reasons, may be able to produce at lower costs [8-10].

- $\quad$ Although management-planning cycles of the WFD look forward until 2021 or even 2027, the WFD related time perspective is much shorter than the envisaged duration of the mining operations, which are expected to last to roughly 2060. Even after closing down the mine, long-term environmental liabilities will remain as mine dumps will demand perpetual treatment.

- Management plans meant to modify current operations are also influencing the prospective amount of these perpetual treatment costs for environmental liabilities, for which accrued provisions must be set up. This aggravates the decision problem. Requirements improving the water body status until 2021 or 2027 should neither be disproportionate at the present time nor neglect long-term financial liabilities.

More specifically, all stipulations for improving the status of the affected water bodies should balance its prospects with the financial burden for the mining company and the increasing risk of societal costs.

\section{Eco-efficiency analysis (EEA)}

\subsection{Methodological background}

Eco-efficiency was first introduced in 1991 by the World Business Council for Sustainable Development as a concept to create more economic value in order to meet human need and improve quality of life while reducing consumption of natural resources and environmental impacts (Schmidheiny [11]). Eco-efficiency 
is a ratio of a measure regarding economic value (to be increased) over a measure of environmental impact (to be reduced) in a life cycle perspective.

The concept has been widely adopted by businesses as a management tool to reduce costs or to improve production processes (Kicherer [12]). Simultaneously, external environmental effects of processes are incorporated into management decisions.

At macro level, the method has found application as indicator of sustainable development within an industry sector or a region (Zhang et al. [13]). To some extent, EEA has drawn the interest of policy-makers as a tool to promote more sustainable practices through public policies. Indeed, the simultaneous consideration of economic value with environmental impacts over the life cycle of a product or process allows to consider environmental external effects and to compare outcomes with social trade-off curves for society (Huppes and Ishikawa [14]).

As a result of such a wide application scope, EEA is characterized by the absence of a detailed standard framework. The economic value can be measured using national accounting indicators, societal cost-benefit indicators or management-oriented methods such as life-cycle costing. The environmental measure is being evaluated with a life-cycle assessment (LCA).

\subsection{EEA applied to assessment of disproportionality of WFD measures}

According to the WFD, the chosen measure should be effective to achieve the good ecological status and cost-effective in comparison to other alternatives. Additionally, costs should be affordable for the stakeholders and proportionate with the benefits of improved water quality. The EEA method is being applied to deliver cost-effectiveness indicators to stakeholders and water managers as input to the discussion of disproportionality (figure 1). Although the method has been tailored to the WFD context, it follows the basic steps of the EEA framework applied to product systems as provided by the ISO 14045 [15].

First, the different measures are being described in order to identify costs and environmental effects relevant for the analysis. Simultaneously, the boundaries of the system under consideration are defined. Second, the effectiveness of the measures over the water quality is assessed at different points in time together with further environmental effects of the implemented technologies. Third, the costs of the measures are being evaluated. Fourth, both environmental and economic effects are combined into eco-efficiency indicators in order to compare the costeffectiveness of the various measures under consideration. These indicators are then put in perspective to provide input over the affordability and disproportionality of the measures.

The analysis takes place in two steps. First, the analysis is being carried out at in-plant level to determine the affordability of the measures and identify potential adjustments by the company (production restrictions, shut-down...). Second, the analysis considers the adjusted measures from a societal perspective in order to support the disproportionality assessment. 


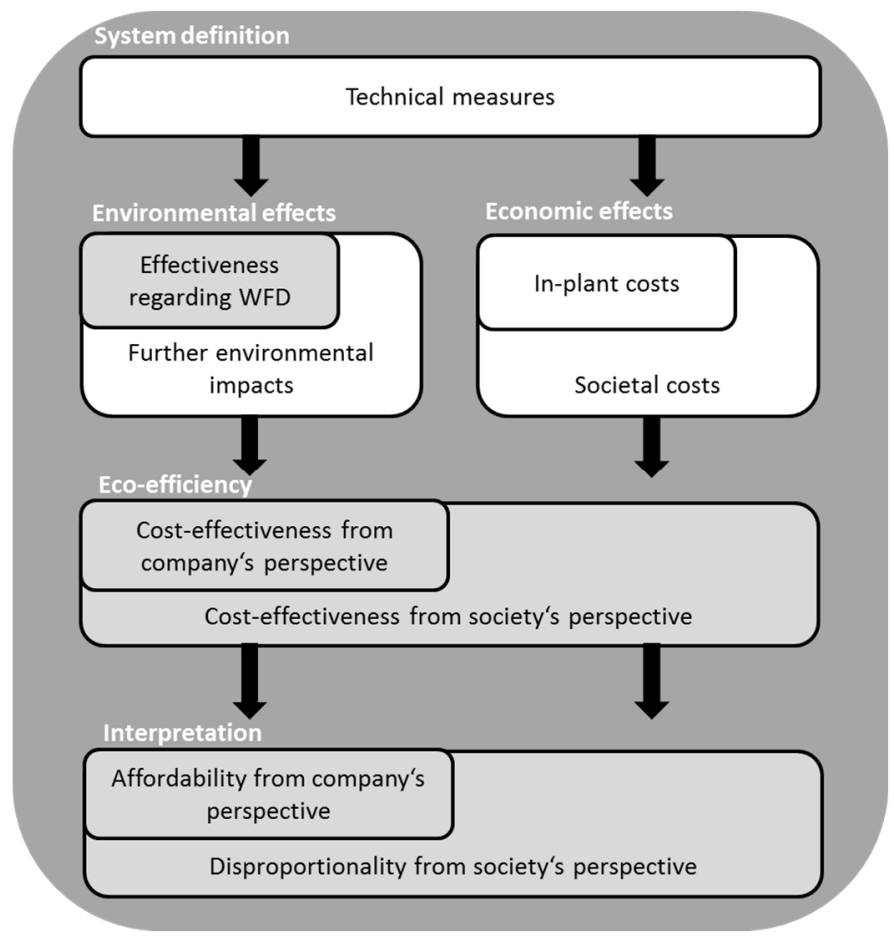

Figure 1: Steps of eco-efficiency analysis for assessing disproportionality.

\subsubsection{Defining measures to be assessed}

By today's state of the technology, no single technical measure is able to reduce the discharge of salt effluent in the Werra/Weser effectively. Therefore, a combination of technical solutions is discussed. Technical options include (i) a pipeline to bypass the river system in part or in total to discharge salt water into the North Sea or at least in the Upper Weser, (ii) the covering of the salt dumps and (iii) innovative processes to reduce salt water emissions when refining the salt.

Those technical solutions differ regarding their effects and time-horizon. Pipelines are end-of-pipe solutions which minimize the effects of salt emissions but not their amount. On the opposite, covering of salt dumps and the introduction of innovative production processes reduce the amount of salt emitted. Pipelines and production process innovations can be implemented within a few years while covering the salt dumps is expected to last over decades. However, it offers a definitive solution to the long-time effects of the run-offs from the salt dumps, which are expected to last over centuries otherwise.

\subsubsection{Environmental effects}

In EEA, environmental effects are normally aggregated using a life cycle assessment (LCA). However, for the current application salt concentrations need to be considered separately as indicators of the WFD measures' effectiveness. 
Hydrological simulation model provides the estimated salt concentrations for chloride, potassium and magnesium for each water body of the river at several points in time [16]. The included time span covers the WFD periods and moreover the mining activities afterwards till the final steady state in 2075 , once the mining activities are over.

Modelled data of salt concentrations from the different water bodies are aggregated into a comprehensive single indicator for the river. Since such aggregation implicitly weights and normalizes the results, different indicators have been tried out in a sensitivity analysis. For instance:

- $\quad$ "Length of water course that meet WFD environmental quality standards for salt" directly reflects the WFD-objectives. At the same time it does not take into account improvements below WFD targets.

- "Average reduction of salt content" takes into account every improvement in salt concentration for each water body compared to the status quo. However, it does not indicate the effectiveness of the measures in meeting WFD targets.

Other, even more sophisticated indicators are considered such as those ones that use a distance-to-target approach and may adequately differentiate between improvements starting from an already very good state and those that start from a worse one.

Results show that measures can improve the water quality significantly. Further, it shows that an immediate shut-down of the production will not be sufficient to meet WFD standards for good water status in the receiving surface waters because the dump sites have become independent pollution sources of too much importance already.

Even though the effectiveness of the measures to reduce salt concentration is at the core of this analysis, a LCA was carried out. The high material- and energyintensity of the WFD measures under consideration justifies to consider further environmental effects in a comprehensive manner. However, results show that (i) greenhouse gas emissions are the most important environmental effects and that (ii) even those effects of energy-intensive measures like pipelines are negligible in comparison to mining operations. For this reason and in order to keep the evaluation simple, those environmental effects have been neglected finally.

\subsubsection{In-plant and societal economic effects}

The economic effects at in-plant level account for the financial expenses by the firm. In the present case, the in-plant effects comprise first the investment and running costs of the technical measures such as the pipelines, the process optimisation regarding salt refinement and the covering of the dumps. Second, the setting up of accruals for liabilities occurring after the shut-down of mining operations (e.g. the costs of handling runoffs from salt waste dumps) are included. Third, sales reduction due to production restrictions will be accounted for as costs in case of insufficient technical measures to meet water quality objectives.

The following principles have guided in-plant cost evaluation. First, only cost differential in comparison to the business-as-usual scenario. Second, life-cycle cost approach has been applied. Third, indicators are used that can be related to 
welfare economic theory, according to which changes in net revenue are relevant (e.g. Freemann III [17]). Expenses or revenues that are passed on from the company to the customers or other stake holders are then excluded. In-plant effects deliver the input for evaluating the ability of the firm to pay.

Additionally, in-plant effects are a requisite for assessing the societal costs of measures. Changes in net earnings from mining activities are welfare effects and are accounted for directly if they occur inside the system boundary.

However, societal economic effects of measures differ from in-plant ones. Tax payments of the company are added as benefits. Additionally, the welfare effect of providing jobs has been considered as the mining activity takes place in a structurally lagging region. Then, labour expenses of the plants surpass the societal opportunity costs of labour creating welfare benefits by themselves.

A shutdown of mines has been considered as possible adjustment of the company to unaffordable measures. While in-plant effects are described by the loss of net earnings to the firm, the social effects depend on the special structure of the potash market. The potash market is determined by distribution of mineral deposits and simultaneously characterized by economic entrance barriers as opening a mine is capital- and time-intensive [9]. In consequence, there are oligopolistic market structures between the potash producers. However, the German producers seem to be rather a price taker because their production capacity is smaller than those of the main competitors [8].

The main market of German mines is located in Europe and as potash production costs are strongly influenced by transportation, German producers might have a cost advantage [8] (Anderson and Dason [18]). Besides, German mines produce magnesium in addition to potash, thus giving the German potash companies the advantage of offering a broader variety of products compared to other potash suppliers.

Societal cost of closing down production in Germany depends on the costs of relocating production towards the main competitors abroad. At the moment, there are worldwide excess production capacities (Koven [19]). Thus, relocating the production may be done at low costs only inducing a transfer of the earnings abroad to another company. However, should worldwide demand for potash rise in future, German production capacities might be missed eventually.

Besides, together with production of potash, environmental burdens are relocated as well because the redundant sodium chloride has to be handled elsewhere. Thus, increasing environmental effects must be considered at those places, where production is moved to.

Further societal costs of closing down production may occur due to price shifts for consumers (Freemann III [17]). Here, price changes in Europe caused by closing down German mines will depend on the interference of rising transportation and changes in production costs.

\subsection{Outcome of EEA and interpretation}

In a further step, environmental effects are combined with economic effects in an eco-efficiency indicator, for instance "costs per kilometre of water course with improved water quality". This ratio is a cost-effectiveness indicator at the same 
time and can be used to compare the cost-effectiveness of the different measures under consideration.

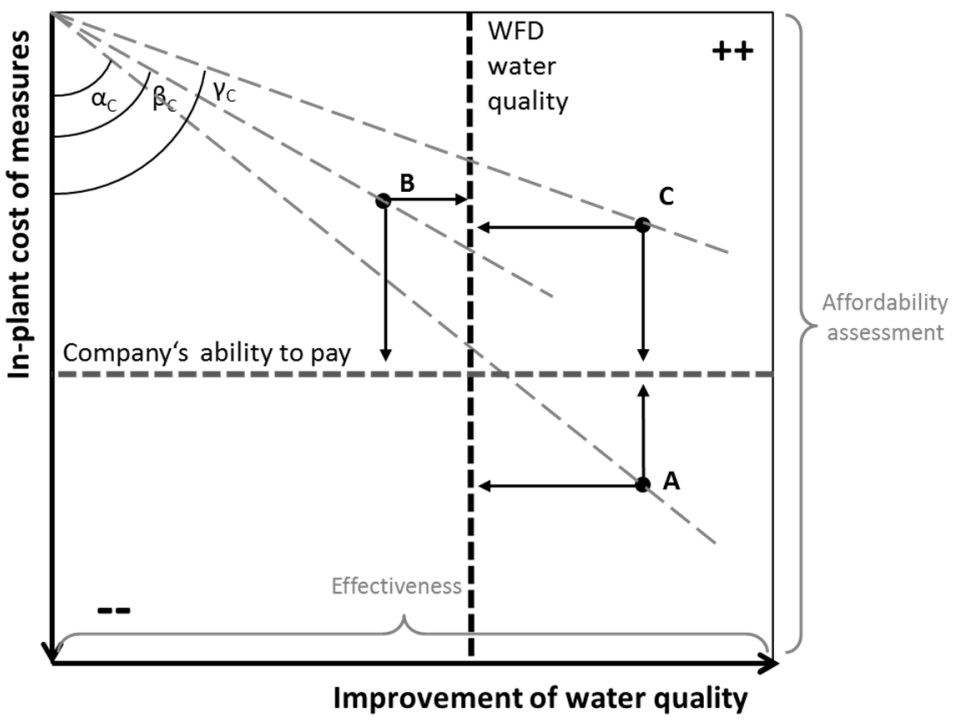

Figure 2: Interpreting in-plant EEA.

The graphical presentation of EEA provides simultaneous information on effectiveness and cost-effectiveness as well as indications over affordability and disproportionality. Figure 2 presents the in-plant EEA while figure 3 refers to the societal EEA. The effectiveness of a measure can be directly deduced from the Xaxis "improvement of water quality". Measure A and C, which are located right from the WFD Water quality target, effectively fulfil the WFD requirements.

The cost-effectiveness information is provided by the eco-efficiency outcome of those measures that meet effectiveness targets. It is given by the slope $\alpha, \beta$ and $\gamma$ of the line linking the origin to the points A, B and C, fig. 2 or fig. 3. Since a greater angle indicates a better cost-effectiveness, measure $\mathrm{C}$ appears to be the most efficient alternative.

Eco-efficiency statement is not redundant with the effectiveness assessment. For instance, measure B is more efficient than measure A although being less effective. Furthermore EEA provides different measures depending on the perspective, and the indexes $\mathrm{C}$ and $\mathrm{S}$ emphasise that in-plant and societal perspective could have different outcomes.

The Y-axis of the in-plant EEA provides input to the assessment for affordability, fig. 2. In the case of in-plant perspective, the ability to pay of the company can be represented by a horizontal line and the affordability of a measure is evaluated according to the distance between the measure and the ability to pay. In our fictive example, only the measures $\mathrm{B}$ and $\mathrm{C}$ are found to be affordable. 


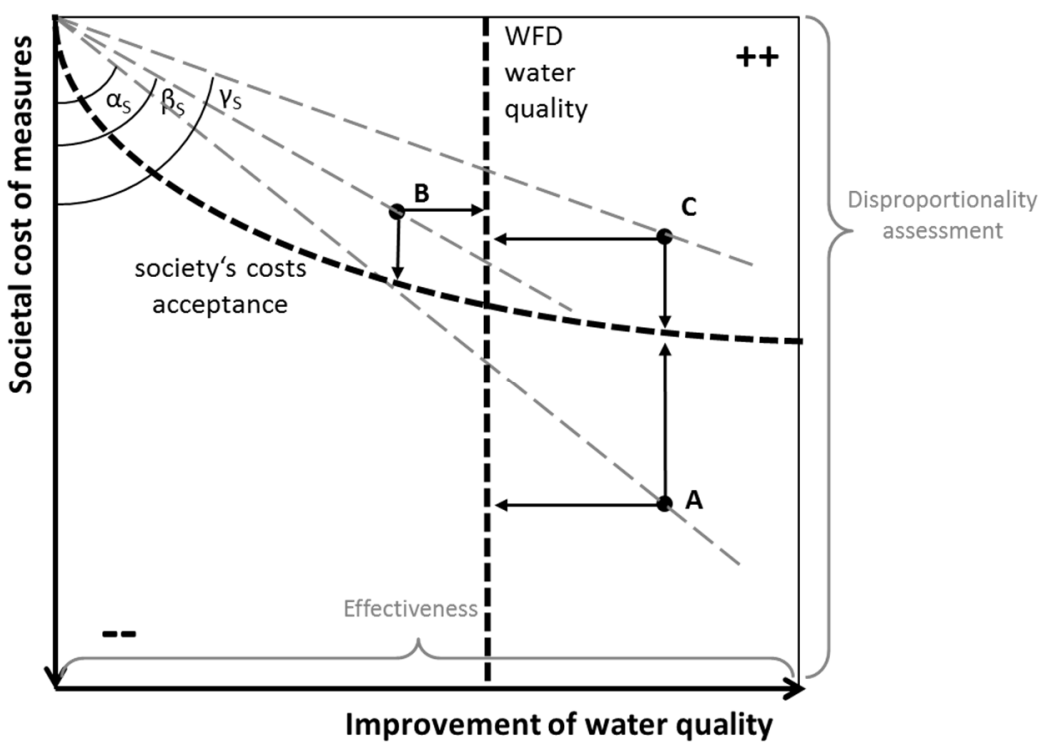

Figure 3: Interpreting societal EEA.

Finally, the societal EEA allows for the judgement of disproportionality by determining whether the costs of measures outweigh the benefits derived from the improvement of water quality (fig. 3). The social trade-off curve indicates the social willingness to pay or social cost acceptance for water quality respectively. On the contrary to affordability, disproportionality will be determined not only by the costs of measures but also by their effectiveness. In figure 3 it is assumed that marginal cost acceptance will decline when quality of water improves. Measure A lies below the curve of social cost acceptance and must be judged as being disproportionally expensive.

Deriving the threshold for the ability to pay of a company and deriving the social trade-off curve seem to the most difficult task of assessment. However, if that information is not available, the eco-efficiency outcomes combined with the effectiveness result can give at least a rank order.

Therefore, the decision process for management plans can be fully supported by EEA since it provides information on the effectiveness of measures, the costeffectiveness of those measures that reach WFD targets and supports the discussion over affordability and disproportionality.

\section{Final remarks}

The aim of the paper was to introduce EEA as an instrument suitable for assessing cost disproportionality in the implementation of EU Water Framework Directive measures. The valuation is being carried out on the basis of the case of a large potash and magnesium mining company located in Hesse and Thuringia that 
discharges salt effluents into the Werra/Weser River. However, only fictive results are being presented since the political decision process is still ongoing.

The EEA puts the effectiveness of the measures in relation to their costs in order to determine the most cost-effective ones and deliver inputs for the assessment of the company's ability to pay (affordability) and the evaluation of disproportionality from a societal point of view. In addition, the life-cycle perspective allows for considering all environmental and economic effects from construction to dismantlement; even though in the present case, further environmental effects have been neglected. Furthermore, the aggregation of the information into distinct economic and environmental indicators allows for an intuitive presentation of the cost-effectiveness of the measure: trade-off between costs and effectiveness are apparent to political decision-makers. Furthermore, the EEA supports the discussion about affordability and disproportionality from both company's and society's perspective. Again, it offers an intuitive way to present the results to decision makers as well. Thus, EEA appears to broaden the toolbox for economic assessment of WFD measure.

The case study has been introduced not only for illustrative reasons, but to show some features that challenge the guidelines of WFD as well. First of all, the affordability of a measure as financial burden imposed on a company can be of more central importance in disproportionality assessment than attributed until now in the guidelines of WFD. This is supported by most recent working papers, European Commission [4] and by findings of the case study:

- Measures are to be carried by a single company according to the polluters-pays principle. However, the company is subject to international competition, which limits latitude in the implementation of measures. Therefore, the risk of a shut-down is to be considered carefully; especially, as it would weigh heavily on an otherwise laggard region.

- When applying polluters-pays-principle, an up keeping of the company is necessary for the implementation of measures which are effective in reaching WFD targets in the long term. An instant shut-down of the site would not be effective because of the perpetual emissions from salt waste dumps which covering is expected to take decades. Moreover, it will leave the long-term environmental legacy to the government and public funds.

Thus, potential structural adjustments of the firm in reaction of the imposed measures have to be taken into account and carefully weighed against the benefit of improving water quality when assessing disproportionality.

Second, disproportionality assessment of measures must reconcile the horizon of WFD with the time frame of mining activities. When preparing the management plans, measures are evaluated regarding their impact until 2027. Opposite to this already demanding task, strategies for managing salt effluents sustainably must consider an even longer horizon as perpetual ecologic effects and long-term environmental liabilities occur. Thus, if the two different perspectives are not harmonized, the risk occurs that measures are decided on for WFD management plans even when they are less effective or efficient in the long run. 
Despite these difficulties regarding its implementation, the WFD has already triggered a shift in the discussion over potash mining practices toward solutions that are more ecologically beneficial while being economically and socially proportional.

\section{References}

[1] European Commission, Directive 2000/60/EC. Official Journal of the European communities 43(L 327), pp. 1-73, 22/12/2000.

[2] European Commission, Common Implementation Strategy for the Water Framework Directive (2000/60/EC) - Guidance Document No 1: Economics and the Environment - The Implementation Challenge of the Water Framework Directive. Produced by Working Group 2.6 - WATECO, European Communities: Luxembourg, pp. 193-199, 2003.

[3] European Commission, Common Implementation Strategy for the Water Framework Directive (2000/60/EC) - Guidance Document No 20: Guidance document on exemptions to the environmental objectives. European Communities: Luxembourg, pp. 13-14, 2009.

[4] European Commission, Addressing affordability concerns in WFD implementation: Resource document for the WG Economics. European Communities: Luxembourg, pp. 7-11, 2014.

[5] Runder Tisch, (eds). Runder Tisch Gewässerschutz Werra/Weser und Kaliproduktion: Empfehlung, Eigenverlag, Kassel, 2010.

[6] FGG Weser, (eds). Gemeinsame Eckpunkte zur Ableitung von Umweltzielen und Maßnahmen gem. Artikel 4 bzgl. Salzeinleitungen für den Bewirtschaftungsplan 2015, Hildesheim, 2013.

[7] Salveti, M., Economic analysis for management of water and aquatic environments, Onema: Vincennes, pp. 52-53, 2013.

[8] K+S Finanzbericht 2013, K+S Aktiengesellschaft Web Site, Kassel, www.k-plus-s.com/de/pdf/2013/fb2013.pdf

[9] Potash Corp 2013 Annual Integrated Report. Potash Corp Web Site, Saskatoon, potashcorp.s3.amazonaws.com/2013 PotashCorp_Annual Integrated Report.pdf.

[10] ICL Annual report 2013, ICL Web Site, repo.icl-group.com/Lists/ ReportsManagement/Financial\%20Reports/2013/Annual\%20report\%2020 13.pdf

[11] Schmidheiny, S., Changing course: A global business perspective on development and the environment, Vol. 1., MIT press: Cambridge, USA, p. 98, 1992.

[12] Kicherer, A., Die Ökoeffizienz-Analyse der BASF. Umwelt Wirtschafts Forum 9(4), pp. 57-61, 2001.

[13] Zhang, B., Bi, J., Fan, Z., Yuan, Z., \& Ge, J., Eco-efficiency analysis of industrial systems in China: A data envelopment analysis approach. Ecological Economics 68(1-2), pp. 306-316, 2008.

[14] Huppes, G. \& Ishikawa, M., An introduction to quantified eco-efficiency analysis (Chapter 1). Quantified eco-efficiency: An introduction with 
applications, ed. G. Huppes \& M. Ishikawa, Springer-Verlag: Dordrecht, pp. 1-38, 2007.

[15] ISO - International Organization for Standardization, Environmental management - Eco-efficiency assessment of product systems: principles, requirements and guidelines, ISO 14045, ISO Central Secretariat: Geneva, Switzerland, 2012.

[16] Bilanzierungs- und Prognosemodell zur Salzbelastung der Werra und der Weser, SYDRO Consult, Runder Tisch Web Site, www.runder-tischwerra.de/show image.php?id=1016\&download $=1$

[17] Freemann III, A. M., The measurement of environmental and resource values. Resources for the Future: Washington DC, pp. 96-99, 2003.

[18] Anderson, J. \& Dason J., Potash transportation cost comparison, Research, Salman Partners Inc. Web Site, Vancouver, salmanpartners.com/lib/files/ Research/2011/February/transportationcomparison.pdf

[19] Koven, P., Potash sector struggles with excess capacity, Financial Post Web Site, Toronto, business.financialpost.com/2013/10/04/potash-sectorstruggles-with-excess-capacity/ 